\title{
INSERÇÃO DIGITAL NA ESCOLA: ESTUDO DA NARRATIVA HISTÓRICA DO PROGRAMA UCA EM UMA COMUNIDADE ESCOLAR
}

\author{
Digital Insertion in School: Study of The Historical Narrative of UCA Program in a School \\ Community
}

Eliana Maria do Sacramento Soares*

Eliana Rela**

\begin{abstract}
Resumo: Apresentamos uma pesquisa com base na memória de pais, alunos, professores e gestores sobre os efeitos da inserção digital representada pelo programa UCA. Para tanto desenvolvemos um estudo de caso, gerando dados por meio de grupos focais. As categorias emergentes: narrativa histórica da efetivação do Programa UCA na Escola; mudanças vividas pela comunidade escolar; ações da escola voltadas especialmente às famílias; e aceleração do contato das gerações mais jovens com a tecnologia permitem dizer que as atividades do UCA repercutiram para além da Escola, estendendo-se aos lares dos alunos e possibilitando que seus familiares também participassem do processo de inclusão na cultura digital.
\end{abstract}

Palavras-chave: Memória. Cultura. Programa UCA. Inserção digital.

\begin{abstract}
We present a piece of research based on the memory of parents, students, teachers and managers, about the effect of digital insertion, represented by the UCA program. For this, we developed a case study, which generated data through focal groups. The emergent categories: historic narrative of the implementation of the UCA program at school; changes experienced by the school community; school actions directed specially to families; and acceleration of contact between younger generations and technologies allow to say that UCA activities caused an impact beyond the school, and extended to students' homes, enabling their families to participate in the process of inclusion in the digital culture.
\end{abstract}

Keywords: Memory. Culture. UCA Program. Digital Insertion.

\footnotetext{
* Pesquisadora e professora no Programa de Pós-Graduação em Educação da Universidade de Caxias do Sul, RS. Doutora em Metodologia do Ensino Superior pela Universidade Federal de São Carlos; Mestre em Matemática pela Universidade Estadual de Campinas; bacharel e licenciada em Matemática pela Universidade Estadual de Campinas. https://orcid.org/0000-0003-4832-5966. emsoares@ucs.br

** É coordenadora do Programa de Pós- Graduação Stricto Sensu - Mestrado Profissional em História e, docente e pesquisadora no Programa de Pós-Graduação em Educação, ambos na Universidade de Caxias do Sul. Doutora em Informática na Educação pela Universidade Federal do Rio Grande do Sul. Mestre em História pela Pontifícia Universidade Católica do Rio Grande do Sul. Graduada em Licenciatura Plena em História pela Universidade de Caxias do Sul.0000-0001-9670-1634.erela@ucs.br
} 


\section{Introdução}

Apresentamos uma narrativa histórica que nasce das representações de alunos, pais, professores e gestores de uma escola municipal da região nordeste do Estado do Rio Grande do Sul sobre os efeitos do processo de inserção digital promovido pelo programa Um Computador por Aluno (UCA). Em 2010, a escola estudada, aqui denominada Escola CJ, foi contemplada pelo programa federal com 523 laptops, que se tornariam ferramenta de apoio às atividades escolares dentro e fora da sala de aula.

O UCA tem sua gênese no Projeto One Laptop per Child (OLPC), idealizado por Nicholas Negroponte, Massachusetts Institute of Technology (MIT), objetivando inserir laptops na prática educativa, a fim de proporcionar aos alunos a possibilidade de experimentar e se expressar por meio da exploração direta dos dispositivos digitais e, então, desencadear mudanças na dinâmica da prática educativa vigente (NEGROPONTE, 1995). Isso poderia levar o aluno a assumir a autoria do seu processo de aprendizagem, desenvolvendo competências importantes para inserir a comunidade escolar envolvida na cultura digital em emergência.

Analogamente no Brasil o programa UCA pretendia transformar a proposta políticopedagógica das escolas participantes, aliando as potencialidades do laptop educacional às práticas educativas. Assim, os ministérios da Educação e da Ciência e Tecnologia foram incumbidos de levar adiante a proposta, processo que teve início a partir de julho de 2005. Em junho de 2006, o Programa UCA foi lançado oficialmente e, em 2010, iniciou-se a distribuição dos laptops nas escolas públicas escolhidas. Ele foi implantado pelo Programa Nacional de Informática na Educação (Proinfo) e a sua realização animou estudiosos, tendo sido objeto de um considerável número de publicações científicas (BRASIL, 2010).

O Programa de Pós-Graduação em Educação da Universidade de Caxias do Sul (UCS) desenvolveu diferentes pesquisas utilizando como objeto de estudo a inserção digital advinda da efetivação do programa UCA na Escola CJ. Em específico, foram desenvolvidos dois projetos de pesquisa, com auxílio do CNPq e três dissertações que tinham como foco caracterizar o processo de redimensionamento das práticas docentes e as mudanças na cultura escolar possibilitadas pela inserção digital em andamento. Para tanto foram constituídos corpus cujos sujeitos eram professores, alunos e gestores, que se manifestaram por meio de grupos focais e entrevistas que aconteceram entre 2012 e 2014.

Dentre as produções desses estudos destacam-se quatro artigos: "Tecnologias digitais: práticas e reflexões no contexto do ensino fundamental" (SACRAMENTO SOARES; VALENTINI, 2012); "O laptop educacional na escola pública: letramento digital e construção de significado" (SACRAMENTO SOARES; VALENTINI; PESCADOR, 2013); "Mudanças nas práticas pedagógicas no contexto da inserção de laptops na sala de aula" (SACRAMENTO SOARES; BRUSTOLIN, 2015); "Mudanças nas práticas docentes no contexto da inserção de laptops numa escola de ensino fundamental" (SACRAMENTO SOARES; BRUSTOLIN, 2016), e "Práticas, representações e mediação: o uso dos laptops educacionais e as intervenções docentes no processo de aprendizagem da educação básica" (SACRAMENTO SOARES; MASCHIO, 2017). Além destes, evidenciam-se as dissertações desenvolvidos por Rigoni (2012); Schonz (2013) e Schmidt (2016), alunas do Programa de Pós-Graduação que realizaram o curso de Mestrado em Educação.

Os resultados das pesquisas indicaram mudanças significativas nas práticas da escola, incentivadas pela novidade proposta pelo projeto. Em relação aos professores, evidenciou-se um 
aumento da preocupação em relação à atuação docente e a consequente revisão da metodologia de ensino habitual, o que revelou um grupo de profissionais comprometido com o contexto da escola, modificado pela presença dos laptops educacionais, e com seu fazer pedagógico.

Revelaram ainda, que a inserção do laptop educacional nesta escola provocou a reconfiguração da sala de aula e mudanças na relação entre alunos e professores. Registramos também que os estudantes participaram mais ativamente do processo educativo, explorando e questionando em um movimento crescente de maior participação. Assim, inferimos que a presença dos laptops contribuiu para a transformação das práticas pedagógicas vigentes, desencadeando um processo de reflexão e redimensionamento da conduta docente, na tentativa de incluir a tecnologia no cotidiano escolar. Em relação à gestão escolar, foram identificadas algumas perturbações geradas pela saída de professores e pela composição de um novo quadro de pessoal, concomitante à chegada dos computadores na escola.

Esses resultados indicam que ocorreu uma ruptura na forma dos professores e alunos atuar em seu cotidiano escolar. Entendendo a prática pedagógica ou escolar como uma prática cultural, as ações realizadas para incluir os laptops nas atividades da escola ressignificaram não só as práticas educacionais, mas também a identidade do grupo como um todo. Isso vai ao encontro do conceito de representação proposto Chartier (1990), uma vez que se infere sobre os efeitos de um determinado contexto, a partir da materialização das práticas de alunos e professores. No caso específico da escola estudada, tal compreensão é possível evidenciando rupturas provocadas pela presença da tecnologia digital no ambiente educativo. As representações visíveis na materialização das práticas são fruto de relações subjetivas e contextuais nas quais, de um lado, atua o docente, desafiado a incluir o laptop em seu cenário de atuação e de outro, o aluno, ao qual se oferecem novas ferramentas para construir significados. Assim, ambos vão construindo um novo contexto, a partir de seus valores, saberes e condições.

Enfatizamos que os resultados apresentados, referentes aos artigos mencionados, dizem respeito a mudanças nas práticas pedagógicas advindas da inserção do laptop na escola em questão. Nesse estudo trazemos uma abordagem em específico, que diz respeito às mudanças ocorridas nas famílias e na comunidade escolar e que se configuram como um estudo de cunho histórico, com enfoque nos possíveis efeitos das práticas educativas exercidas na escola no processo de inserção digital representado pela presença dos laptops educacionais para além dos muros da escola. Para tanto, foi realizado um estudo de caso, tomando como objeto de análise as memórias de professores, de alunos e de pais dos alunos envolvidos no processo.

\section{Metodologia}

Para a escrita da narrativa histórica a que esta investigação se propõe, optou-se por partir do conceito de representação na história cultural, uma vez que o estudo envolve o depoimento direto dos indivíduos envolvidos no contexto enfocado: uma entrevista de História Oral (com a professora coordenadora do Programa UCA na escola) e o testemunho de grupos focais de alunos, pais e professores.

A representação é, pois, um dos conceitos centrais da história cultural: nesta, os elementos que compõem uma narrativa são invariavelmente problematizados de acordo com as interpretações e dos objetivos de leitura de cada historiador, ou seja, são formados por suas representações. Seus limites são, portanto, os limites de mundo de quem a constrói, e cada pessoa pode vê-la desde diferentes perspectivas. O discurso dos historiadores torna-se, assim, a materialização de práticas e de significados particulares. Roger Chartier afirma, nesse sentido, que as representações são 

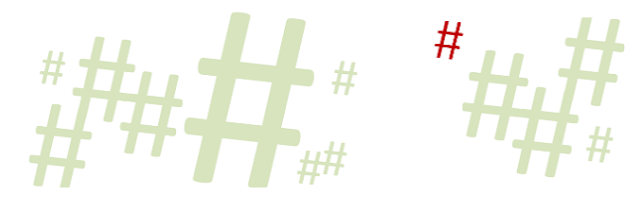

socialmente construídas e se definem na relação de uma imagem presente com um objeto ausente (através de uma memória que o indivíduo ou coletivo selecionou para representar o fato); o autor vê, assim, na história cultural, a finalidade de "identificar o modo como em diferentes lugares e momentos uma determinada realidade social é construída, pensada, dada a ler" (CHARTIER, 2002, p. 17).

A escolha do estudo de caso para narrar a história do Programa UCA na escola em que ele foi aplicado justifica-se a partir do momento em que "o foco se encontra em fenômenos contemporâneos inseridos em algum contexto da vida real" (YIN, 2005, p. 19), e possibilita a compreensão de um acontecimento sob diferentes aspectos.

Para gerar os dados, foram consultados três grupos focais: um com sete alunos; outro com cinco professoras e o último com três pais de alunos; além de ter sido realizada uma entrevista de História Oral com a professora coordenadora do Programa na escola. A opção pelos grupos focais é uma alternativa metodológica de acesso a informações que se caracteriza como um debate aberto e acessível a todos, em que os assuntos são de interesse comum ao grupo e as diferenças de status entre os participantes não são levadas em consideração (BAUER; GASKELL, 2008). Sobre a metodologia da História Oral, Alberti (2015, p.15) afirma que ela se ampara e sobretudo em entrevistas individuais semiestruturadas, com "indivíduos que participaram de, ou testemunharam acontecimentos e conjunturas do passado e do presente".

Para o tratamento dos dados gerados, as professoras são identificadas neste texto por designação alfanumérica, de forma a preservar suas identidades. Assim, tem-se: P1, de Ciências e Matemática, que atualmente já não trabalha mais na escola; P2, de Artes, que permanece na instituição; P3, integrante da equipe gestora na época do UCA e ainda hoje funcionária da escola; e P4, professora de séries iniciais, que não está mais no estabelecimento. Todas fizeram parte do programa UCA na escola, utilizando os laptops recebidos pela escola. Ressaltamos que as regras da escola, no período analisado, não permitiam o uso de celulares no contexto pedagógico.

Quanto aos alunos que participaram da pesquisa, seis eram do sexto ano e um era do sétimo ano do Ensino Fundamental; destes, dois estão na escola desde o primeiro ano, três desde a Educação Infantil, um desde o segundo ano e um desde o quarto ano, tendo feito o pré-escolar na escola. Todos vivenciaram a época de implantação do programa UCA. Os alunos foram identificados por A1, A2, A3, A4, A5, A6 e A7, também como forma de preservar o sigilo.

Os demais sujeitos consultados foram uma mãe e dois pais, indicados por PA1, que se refere ao pai de uma aluna que está na escola desde o pré; PA2, o pai de outra aluna que iniciou na escola na Educação Infantil, mas na metade do primeiro ano mudou-se de cidade, retornando em 2016 para o $4^{\circ}$ ano; e PA3, mãe de dois alunos que estudaram na escola, dos quais um, desde a Educação Infantil até o $8^{\circ}$ ano - hoje no Ensino Superior - e o outro que permanece na escola.

A entrevista na modalidade História Oral foi realizada com uma professora que está na escola desde 1991 e que era responsável pelo laboratório de informática na época em que ele foi equipado e no qual também foi realizado o programa UCA. Ela acompanhou e coordenou todo o processo de implantação e desenvolvimento do projeto, tendo sido responsável direta pela formação dos professores.

As falas dos grupos focais e a entrevista individual foram registradas por meio de gravação, com aval dos participantes. O conteúdo gerado foi ouvido e transcrito com o objetivo de captar o sentido dado pelos sujeitos participantes aos efeitos da implantação e do uso dos laptops na escola, o que se manteve enquanto prática e o que foi modificado. 
Os dados foram tratados com base no que propõem Moraes e Galiazzi (2007) na teoria da Análise do discurso, e o estudo considerou os resultados das pesquisas já realizadas e mencionadas anteriormente e teve conceitos relacionados à história cultural e a cultura digital como fios condutores. Nessa perspectiva, o exame do corpus buscou entender o sentido que os participantes construíram enquanto sujeitos envolvidos no cenário de inserção digital. Esse sentido foi criado, como anteriormente mencionado, a partir de seus valores, saberes e condições, vinculado à sua forma de atuar no cenário escolar em questão.

Do movimento de unitarização e de categorização dos discursos culminou a identificação de categorias emergentes. Para analisar as informações que constituem o corpus, foi levado em conta, ainda, o conceito de representação cunhado por Chartier (1990), buscando compreender de que maneira a inserção digital na escola afetou as suas práticas pedagógicas, através de continuidades e rupturas, dificuldades e avanços.

\section{Resultados e discussão}

A análise das falas dos participantes possibilitou identificar representações quanto ao processo histórico do programa UCA na escola estudada. Tais representações referem-se a mudanças vividas pelas famílias e pela comunidade; a mudanças implantadas na escola para viabilizar o uso dos laptops; e nas relações estabelecidas com os atores, em especial com as famílias, depois da introdução dos computadores; à aceleração do contato das gerações mais jovens com a tecnologia; e à autopercepção dos sujeitos envolvidos no contexto de uso dos laptops na escola. Para apresentar e discutir esses aspectos, são consideradas as categorias emergentes expostas a seguir.

A primeira categoria refere-se à narrativa histórica da realização do Programa UCA na escola em questão, desde a sua idealização. Sobre esse aspecto, a professora coordenadora (PC) comentou que a Secretaria Municipal de Educação (SMED) ofereceu um curso de capacitação para o trabalho com tecnologia, em janeiro de 1997. Desse curso, participaram ela e alguns professores e, já no mês de março daquele ano, foi iniciada a preparação com os alunos, mesmo tendo apenas cinco computadores no laboratório de informática, conseguidos pelos pais e pela escola por meio de doações. A professora PC lembra1: "dividíamos as turmas: vinha metade da turma num período, no outro período vinha outra metade da turma. E foi assim por um bom tempo; a gente fez dessa forma".

A docente destaca que o envolvimento e o comprometimento dos pais dos alunos foi uma constante na formação de seus filhos para o uso dos dispositivos. A participação dos pais e a colaboração destes com os professores também são evidenciadas por PA2:

[PA3 e PA1] atuam no Conselho há muito tempo. Eu estou desde 2013. Por isso conhecemos a história dos lepinhos ${ }^{2}$ a fundo. O [nome da escola] é uma escola onde pais e professores são muito atuantes, as reuniões são mensais, tem reuniões com presença de 30/40 pais. (informação verbal)

\footnotetext{
${ }^{1}$ Reportam-se às falas dos professores, alunos e pais de alunos com base nas entrevistas a eles aplicadas. Todas as citações diretas e indiretas que se referem a suas representações são, portanto, oriundas de informação verbal. ${ }^{2}$ Lepinho é o apelido que os estudantes envolvidos no projeto UCA deram aos laptops recebidos pelas escolas.
} 
A notícia do Projeto UCA chegou no ano de 2007, com previsão de que as escolas contempladas receberiam um laptop para cada aluno. A equipe diretiva da Escola CJ encaminhou, então, sua candidatura, contemplando as exigências do edital de seleção. Foi feito um sorteio com as escolas participantes da seleção, e a instituição foi contemplada com 525 laptops, recebidos em 2010 .

Em relação ao primeiro ano de implantação do projeto, a professora P2 afirmou que "o uso foi aos poucos, pois foi necessário [sic] adequações com a infraestrutura. Foi um processo de testes até encontrar a forma adequada".

Sobre a reação das famílias, PC lembrou:

\begin{abstract}
As famílias ficaram muito impactadas. $\mathrm{Na} 1^{\mathrm{a}}$ reunião compareceu a grande maioria. Eles questionavam sobre como seriam usados [os computadores], se poderiam levar para casa. No decorrer das conversas compreenderam que seria mais seguro para os alunos usarem na escola. Eles acompanharam todo o processo, eles queriam saber como seriam as aulas, o que poderiam acessar, qual recurso usariam. Eram perguntas frequentes. (informação verbal)
\end{abstract}

Os professores participaram de encontros de formação ao longo de 2010 e 2011, ano em que iniciaram o uso dos dispositivos de maneira mais sistematizada. A manutenção dos equipamentos foi difícil, pois o laboratório do MEC responsável por essa demanda foi extinto e, em alguns momentos, a Escola CJ contou com a ajuda de professores da UCS para auxílio técnico.

Entrecruzando os discursos dos professores, dos pais dos alunos e da coordenadora, percebe-se um grupo envolvido e comprometido com a adequação da escola ao processo de inserção digital, buscada nas diferentes formas de adicionar recursos digitais à dinâmica das ações pedagógicas da escola.

O conceito de cultura digital diz respeito a uma série de comportamentos cuja gênese e contexto estão relacionados de forma significativa à presença da tecnologia digital no cotidiano e no contexto social. As diferentes formas de comunicação, de representação e de busca por informação que a tecnologia oportuniza possibilitam maneiras alternativas de comunicação também a nível pedagógico e interpessoal, que por sua vez transformam as práticas educativas e sociais (LEMOS, 2009).

As narrativas dos professores permitem dizer que um dos aspectos buscados pela escola ao se apropriar das ferramentas e recursos dos laptops está relacionado ao uso crítico e significativo dos recursos digitais, o que constitui uma forma de letramento digital, porque implica uso das tecnologias para a inclusão social e cultural. Ser letrado digital é mais do que saber operar laptops, requer conhecer e saber fazer uso das ferramentas e recursos tecnológicos disponíveis, dando significado às informações, imagens e sons que constituem a linguagem digital. As informações fornecidas pelos participantes revelam que esse processo iniciou-se com eficácia na Escola CJ, onde os alunos e os professores buscaram aprender a usar os recursos dos laptops com vistas a um mesmo objetivo, que foi efetivar o processo de aprendizagem.

A segunda categoria emergente da análise das falas compreende as mudanças vividas pelas famílias e pela comunidade escolar por ocasião da inserção dos computadores. Seguindo a narrativa da professora PC, o processo de integração dos estudantes na cultura digital pelo uso pedagógico dos laptops na escola reverberou nas ações dos pais, que deram depoimentos frequentes de como seus filhos os ensinavam a usar o computador e outros aparelhos eletrônicos, 
como o celular e televisões de modelos mais recentes. Isso permite concluir que o processo de inclusão dos estudantes na cultura digital aconteceu para além dos muros da escola: "parece que algo forte foi aprender a explorar os recursos tecnológicos para compreender o [seu] funcionamento, o que a escola incentivou a ponto de os estudantes levarem para outros contextos" (Professora PC).

Ao refletir sobre as mudanças pedagógicas, a professora coordenadora PC também disse que:

A forma de lidar com o desconhecido, de como entender o funcionamento dos laptops foi muito rico [sic], de forma que isso os ensinou a explorar, embora em termos de aprendizagem conceitual não tenha ocorrido mudanças significativas, como era minha hipótese inicial, de que a tecnologia poderia auxiliar para uma aprendizagem melhor. (informação verbal)

PA2, quando perguntada sobre a aprendizagem, porém, recorda que os computadores eram equipados com programas educativos: "lembro bastante do desenvolvimento pedagógico, o lepinho tinha vários programas: para identificar cores, identificar palavras, fazer relações" - e PA3 corrobora com a representação do pai PA2 ao relatar que seu filho, o aluno A6, chegava em casa contando: “'Mãe, hoje a gente fez jogo!'. Ele ia para casa eufórico. Era uma novidade, agregava muito para eles".

Acerca das mudanças ocorridas nas famílias com a chegada e o uso dos computadores, PA2 fez uma análise histórica da evolução tecnológica em curso e de suas implicações na vida cotidiana:

O processo tecnológico teve uma evolução muito rápida. Em 2010 quem é que tinha um celular? E como eram os celulares? O processo não era tão fácil como hoje. Hoje uma criança com 7/ 8 anos pega um celular e sabe lidar. No tempo da implantação do projeto UCA, os alunos tiveram também que se adaptar a tecnologia. Hoje se for fazer esse projeto, na minha opinião, será muito mais fácil para a criança, pois tem esse convívio em casa, o toque, o touchscreen. Quem tinha notebook na época? Eram poucos [...] nós [adultos] temos medo; e eles não têm. Eles não têm esse medo porque já foram inseridos nessa cultura aqui na escola. Quando começaram a se desenvolver já foram se desenvolvendo com a tecnologia, então isso é o normal para eles. (informação verbal)

Ele ressaltou, ainda, que o fato de:

O professor fazer o curso; designar um professor para coordenar essa área; cuidar da manutenção, arrumar os armários... tudo tem um custo, tudo tem um tempo; e a escola não ficou por menos, deu continuidade. Quanto isso agregou na educação dos nossos filhos! Isso só melhorou o desenvolvimento deles. A gente realmente vinha e acompanhava. Ele [o filho, A6] desenvolveu muito bem, pois ainda hoje, em casa, ele mostra esse desenvolvimento quanto à destreza no manuseio. (informação verbal)

P2 também reconhece os benefícios do projeto:

Eu estive na escola por um ano, depois mudamos de cidade e voltamos. Eu procurei colocar [a filha] de novo aqui. Tenho certeza que muitos pais resolveram colocar os filhos aqui, e não é nada fácil conseguir vaga aqui, [a escola] é muito procurada, difícil de entrar aqui. Tem vários pais que matricularam aqui exatamente pelo projeto. Todos os pais falavam de boca cheia que a escola tinha o projeto Um Computador por Aluno. Falávamos com orgulho. (informação verbal) 
O efeito do programa nas famílias está, ainda, no discurso de PA1 ao afirmar que, em sua casa, a esposa aprendeu usar o computador com a filha, aluna da escola; e quando PA3 chama à atenção o fato de que a escola, de certa forma, supre carências de uma educação digital que não é possível da mesma maneira em casa:

Lembro quando eles começaram confeccionar os cartões. Um dia [A6] chegou com o cartão de Natal feito no lepinho, no dia das mães [...]. A escola educou nossos filhos, pois nós, pais... Nossa geração não teria como educá-los, pois o computador não foi da nossa geração, nem da nossa formação, mas a escola educou da maneira certa. (informação verbal)

Nesse sentido, o professor P1 comenta sua formação, dizendo que aprendeu "a trabalhar de forma integrada com o projeto UCA". Essa verbalização tem eco nos demais depoimentos dos professores que destacaram a forma colaborativa com que atuaram no decorrer do projeto, evidenciando a partilha de anseios e de avanços, que é importantíssima em termos de trabalho em equipe e pode reverberar ao longo da carreira docente, dando resultado inclusive em outros contextos.

A terceira categoria emergente refere-se às ações que a escola realizou, especialmente em relação às famílias. Uma delas foi a organização de oficinas, pelas quais os filhos mostraram aos pais o que aprenderam usando os laptops. A professora coordenadora PC destacou, a propósito:

Eles sentavam com os filhos, e os filhos mostravam o que eles trabalhavam. Os pais amavam isso. Com isso alguns pais aprendiam. A direção organizava oficinas ou eventos onde os pais acompanhavam e conheciam o que os filhos estavam fazendo, como usavam e o que aprendiam. Isso aconteceu também com os alunos da educação infantil. (informação verbal)

PA2 também citou as oficinas:

De tempos em tempos, o colégio pedia que os pais viessem e acompanhassem junto com o filho, a filha, o processo de aula. A gente vinha, sentava do lado e faziam a demonstração do que estavam estudando no trimestre. A maioria dos pais vinha. Eu falo por mim, eu vinha, sentava do lado, e ela [a filha] mostrava as atividades. (informação verbal)

Outro fato destacado foi o estabelecimento das regras quanto ao uso dos equipamentos. Sobre isso, a professora coordenadora PC relatou:

Estava previsto que os laptops seriam levados para casa. Cada aluno deveria ter o seu e os pais assinariam um termo de responsabilidade. Alguns pais acharam que isso seria perigoso: medo de roubo. Assim, de comum acordo, decidiram por usarem os laptops na escola, e eles ficariam em armários, sob a guarda dos alunos, e cada aluno teria o seu. (informação verbal) 
Além disso, A1 comentou sobre duas regras importantes estabelecidas à época: "tinha de limpar bem a mesa, não podia ter nem farelo de borracha, pois nos ensinaram que isso danificava o lap. A outra regra era: quando terminasse, guardar e colocar [o computador] para carregar". A4, complementando, lembrou que "para guardar, sempre tinha dois ajudantes, por ordem alfabética, um menino e uma menina; ajudavam levar os laps até o armário de madeira, que tem na sala de aula até hoje". A7 sintetizou as regras incluindo uma atitudinal da qual se lembrou, além das procedimentais: "nada sobre a mesa; colocar sempre na ordem de número; não segurar pela alcinha para não deixar cair; ligar e esperar a luzinha acender; aí [depois disso] poderia usar; e não podia acessar rede social"'.

A4 relatou outro cuidado relacionado ao manuseio dos equipamentos:

\begin{abstract}
Usamos sempre o mesmo lap, cada aluno tem o seu desde o primeiro ano. Eu sei porque descobri que dava para mudar a capa de fundo. E troquei a minha para roxo, então sei que aquele é meu. Todos os anos, no final do ano, trocam a fita que identifica a turma, mas o nome continua o mesmo. Acho que todas as regras foram boas e bem importantes. (informação verbal)
\end{abstract}

Sobre a forma de uso dos recursos, PA2 sintetizou:

\begin{abstract}
Então isso [as regras] educou as crianças no que podiam acessar, e fazer um julgamento do que era bom e do que não era. Outra coisa que a meu ver foi importante, [foi] o planejamento dos professores: tinham organização para o uso. Eles realmente tiveram um começo com modelo correto, como deveria ser para todos. (informação verbal)
\end{abstract}

Essas narrativas mostram planejamento da escola na busca de criar formas de uso responsável, tanto no cuidado com os computadores, como para desenvolver uma atitude crítica diante do seu uso, contribuindo para a fluência digital dos envolvidos. Segundo a professora PC, por exemplo, os alunos eram orientados sobre o acesso a sites, e, quando acontecia algum acesso inadequado, havia um alerta por parte da escola.

Além disso, sabe-se que formação continuada dos professores é também aspecto essencial nos processos de uso pedagógico das tecnologias para a inserção das práticas docentes na cultura digital. Refletir sobre a própria prática e estar aberto aos processos de inovação relacionados ao uso dos recursos digitais, promovendo seu próprio processo de letramento digital, são elementos centrais para o docente atuar em projetos alinhados a cultura digital. Para que tais condições fossem viabilizadas, a Escola CJ promoveu ações no sentido de viabilizar que os professores pudessem refletir sobre formas de redimensionar suas ações. Sobre isso, a professora coordenadora PC comentou em sua entrevista:

Todos os professores receberam os laptops e todos receberam formação. No primeiro ano aconteceram resistências por parte dos professores. Professores saíram da escola, por conta do projeto. E os professores que vinham para a escola vinham sabendo do projeto e de que precisavam da formação. (informação verbal)

A forma de representar a colaboração entre os pares, a maneira de atuar, o trabalho em equipe, a forma de explorar os equipamentos, de tomar o erro como possibilidade de reorganizar 
o caminho para aprender, dentre outros aspectos que foram desenvolvidos pela presença dos laptops e dos recursos digitais nas salas de aula, evidenciam apenas algumas transformações desencadeadas pela presença da tecnologia no cenário escolar, mas que o modificam substancialmente.

As ações realizadas pela escola dizem respeito às características da cultura digital na medida em que os sujeitos fazem uso dos recursos tecnológicos em seu cotidiano, ressignificando suas ações e sua forma de ser no contexto social a partir de sua relação com esses recursos, recombinando as práticas existentes. Essa forma de unir práticas antigas a novas, por meio da tecnologia, consiste em um dos aspectos da cultura digital, conforme entendida por Lemos (2009), como reconfiguração sociocultural a partir de novas práticas combinatórias.

A quarta categoria que emerge das representações é a aceleração do contato das gerações mais jovens com a tecnologia. Os depoimentos dos pais revelam que estes se percebem parte de uma geração que não teve contato com o computador, e que a escola, no entanto, educou seus filhos para o uso adequado dessa tecnologia. Eles destacam o empenho da instituição em incluir a tecnologia em seu contexto. Quanto a isso, a professora coordenadora PC relatou que:

Pais que sabiam do contexto das tecnologias na escola buscavam matricular seus filhos [nela], pois os professores utilizavam tecnologias. Parece que, ao se esforçarem para isso, eles estavam prevendo a importância de seus filhos estarem num lugar como esse, levando em conta as competências que desenvolveriam. (informação verbal)

Na fala dos pais, a inserção do programa UCA na Escola CJ foi fator de aceleração do contato de seus filhos com a tecnologia. Nesse sentido, os alunos relataram: "eu tinha computador em casa, só que não mexia. Comecei mexer com o lepinho, e foi fácil de aprender" (A1); "eu não tinha computador nem celular em casa. Quando cheguei na escola e comecei usar o lap, foi uma descoberta" (A5). O aluno A4 acrescentou "lembro que foi muito difícil pra mim, porque eu dependia dos meus pais para mexer no computador. Lá em casa até tinha, mas usava só para jogar. Depois que comecei usar o lap melhorou muito".

A1 citou, ainda, o processo de aceleração do contato com a tecnologia dizendo: "sem os lepinhos, acho que eu teria aprendido usar o computador lá pelo terceiro ano. O lepinho [me] ajudou muito [a] aprender fazer pesquisa e usar o mouse". Com efeito, ele iniciou o uso dos laptops na educação infantil. A aluna A4, também entusiasmada, falou "eu acho bem importante colocar as crianças na frente da tecnologia. Por exemplo, eu hoje sei arrumar wifi no computador, aprendi com a professora".

Por fim, o depoimento de A5 provoca diferentes reflexões, seja no âmbito pedagógico, seja na dimensão de oportunidades para os familiares adultos:

O nível de ensino aqui na escola não seria o mesmo sem os lepinhos, além de que teríamos mais dificuldades para aprender, e os professores teriam mais dificuldades para nos ensinar. O lepinho é uma fonte mais fácil para os professores nos ensinarem, que enquanto aprendemos estamos nos divertindo. Em relação à tecnologia, acho que é muito importante essa nova geração aprender com a tecnologia. Por exemplo, lá em casa, os meus pais tem dificuldade em mexer com o celular deles, então se dá algum problema, eles recorrem comigo [sic]. Minha mãe não sabia baixar whatsapp, fico abismada como eles não conseguiam mexer. Eu sinto que é por que a gente teve a tecnologia junto da 
nossa infância no colégio. Isso ajudou a gente, e eles [os pais] não tiveram. (informação verbal)

Em relação a esse aspecto, P1 esclareceu, em uma narrativa carregada de sensibilidade:

\begin{abstract}
Muitos alunos não tinham acesso ao computador em casa, e o fato de terem aqui na escola foi muito positivo para vida deles. Embora com o tempo eles precisassem utilizar em duplas, o fato de usarem o equipamento agregou muito, inclusive o fato de escolherem cursos na área tecnológica. A escola ajudou com a alfabetização tecnológica deles. (informação verbal)
\end{abstract}

PA2 refletiu igualmente sobre a repercussão do projeto na vida dos alunos, comparando-a à experiência de sua filha:

[A3 e A7] são geração Escola CJ, como chamamos. [A5] não, começou, saímos e voltamos. Eu senti diferença lá fora. Eles aqui evoluíram, ela começou e parou, porque para onde fomos não tinha nada, era outro padrão de escola, outro modelo, outra cidade. Podemos dizer que ela sentiu bastante. Quando voltamos [...], eu vim antes, fui na central de vagas [da cidade], fiz e aconteci para fazer ela [sic] voltar para essa escola. (informação verbal)

Ao fazer a narrativa dessa memória, PA2 se emocionou muito ao lembrar do esforço para alcançar o objetivo de matricular novamente a filha na escola que oferecia um computador para cada aluno.

PA3 narrou, também, que:

\begin{abstract}
A professora coordenadora passou as férias trabalhando na escola, estudando, organizando para que quando começasse o ano letivo, os alunos já tivessem tudo pronto para utilizar. Os professores, quantas noites foram fazer curso para se capacitarem e implementarem com as crianças! Foi muito empenho e doação dos professores. Eles tinham a alegria de dizer "temos um computador por aluno!". Na época nem as escolas particulares tinham o que nós tínhamos lá no começo de 2010. Foi um orgulho muito grande para nós pais e para nossos filhos. (informação verbal)
\end{abstract}

PA1 evidenciou, por sua vez, sobre a participação das famílias, que, nesse processo histórico de implantação do projeto, desde a candidatura no ano de 2007, sempre foi ativa: "A escola sempre deu liberdade para estarmos presente. A escola vem mantendo os laps porque é uma escola que se empenha".

De fato, a professora PC, em sua narrativa, mencionou que os pais sempre se sentiram parte da escola e que o fato reverberou na forma como o UCA aconteceu e como eles se envolveram. Ela relata:

[Há] um grupo de professores muito unido, muito bom e com trabalho em equipe, o que foi fundamental para sustentar as mudanças na conduta, trocas de ideia e colaboração para reflexões teóricas [...]. Os cursos ajudaram, mas o que aconteceu depois foi que cada professor foi fazendo e, na discussão entre eles, foi se aprendendo a como lidar e usar os recursos. (informação verbal) 
P1 lembrou, para concluir, que os alunos achavam muito bom trabalhar juntos, discutindo e aprendendo e, principalmente, julgavam interessante o fato de os professores estarem discutindo com eles. "Se trocava muito o que cada um descobria, em termos de como utilizar, como acessar. Foi uma postura importante para entender e aprender como o equipamento funcionava, que recursos tinha e, para isso, tanto professores quanto alunos se uniram para aprender".

Entende-se, pois, que as narrativas demonstram mesmo esse movimento da escola e da comunidade em direção à conquista do lugar de cada indivíduo e de cada cultura no contexto digital, como possibilidade de aprendizagem e de inclusão. Lemos (2009) afirma, nesse sentido, que a cultura contemporânea, quando associada às tecnologias digitais, cria uma nova relação entre a técnica e a vida social, que ele denomina cultura digital. Nela, os fluxos de informação e de comunicação são praticamente instantâneos e, por isso, resultam em mudanças coletivas relacionadas sobretudo ao registro e à socialização de fatos e de ideias, permitidos pelos recursos tecnológicos. Nesse sentido visualiza-se, também e consequentemente, quando há desconhecimento de como utilizar esses recursos tecnológicos, a possibilidade de crescer uma nova geração de "analfabetos tecnológicos", colocando novamente a classe menos favorecida à margem da sociedade. Com efeito, Lévy (1993), em uma análise do futuro do pensamento nesse cenário, já concluía que a sociedade contemporânea estava diante de "novas tecnologias intelectuais".

\section{Considerações finais}

A fim de analisar como se deu a implantação do programa UCA em uma escola municipal da região sul do Brasil, realizou-se um estudo de caso baseado na representação de quem esteve direta ou indiretamente envolvido no projeto: alunos, pais e professores. Buscou-se, assim, promover uma narrativa histórica coletiva que permitisse entender o impacto dessa iniciativa nas práticas escolares e na comunidade.

Os resultados desse estudo indicam que esse processo foi um marco na história da escola estudada, evidenciando que a instituição sempre esteve aberta a incluir em seu cenário recursos digitais que pudessem modernizar e potencializar sua prática educativa. As mudanças vividas pelas famílias e pela comunidade escolar mostram a presença atenta dos pais no processo, por meio da Comissão de Pais e Mestres, além da preocupação da escola em participar de iniciativas que culminassem com melhorias para as ações educativas que incluíssem a tecnologia digital.

Os movimentos de reflexão dos professores que levam à revisão de suas práticas, a reconfiguração da sala de aula, as mudanças nas relações interpessoais entre eles e alunos são materializações das representações dos envolvidos que surgem como consequência de um redimensionando da cultura escolar desencadeado pela presença de um novo elemento nesse contexto: os laptops educacionais.

Para além das mudanças na dinâmica pedagógica pode-se ainda inferir que a presença da tecnologia no cenário escolar também repercutiu na relação da escola com as famílias. Isso fica visível nas ações planejadas envolvendo pais e filhos em parceria para se apropriar dos recursos digitais, a fim de se inserir na cultura digital vigente. Assim, a escola foi mudando sua cultura tanto no que tange às ações com seus alunos, mas também com a comunidade representada pelos seus pais e familiares.

O envolvimento dos professores e da gestão escolar nessa inclusão na cultura digital por meio do uso de tecnologias na ação pedagógica também é outro fator que criou o cenário propício para que o UCA encontrasse na Escola CJ um terreno fértil. Resultado disso foi bons frutos em 
forma de mudanças ocorridas em vários aspectos, principalmente na dinâmica e na organização do espaço da sala de aula, na relação entre professores e alunos, na forma de os alunos trabalharem e acessarem informações úteis para seus estudos, e no envolvimento das famílias que também entraram no processo de alfabetização digital, através de seus filhos, alunos da escola.

Os resultados evidenciados permitem inferir que a presença dos laptops na Escola CJ auxiliou no processo de inserção digital, aumentando o fator de conectividade dos envolvidos. $\mathrm{O}$ acesso aos equipamentos na Modalidade 1:1 fez dos alunos portadores de um dispositivo que lhes permitiu criar seu caminho de acesso à informação e os instigou a explorar recursos disponíveis. Esse formato sustentou processos de exploração de dados e de interação entre os estudantes e com seus professores, conforme relatos dos participantes da pesquisa. Essa inferência está de acordo com as pretensões de Negroponte (1995) quando ele previu que a inserção de laptops na prática educativa poderia desencadear mudanças na dinâmica da prática educativa vigente. Outro aspecto considerado coerente com as ideias desse autor é que a presença dos laptops educacionais no cenário escolar possibilitou a mobilidade e conexão a redes de informação e conteúdo, no ambiente escolar, o que resultou ações de aprendizagem mais focadas na ação e na autoria do aluno.

Ao finalizar essas reflexões, destaca-se que as transformações no cenário escolar, reverberado para além dos muros da escola, incluindo as famílias no processo, evidencia uma prática social que atribui significado a uma ação realizada por meio da inclusão de recursos das tecnologias digitais, conforme comentário de Almeida (2005).

Encerra-se dizendo que as ações relacionadas à implementação do Programa UCA na Escola CJ foram significativas, abrangentes e em consonância com o seu tempo, ao promover ações de inclusão à cultura digital no cenário social e educativo em questão.

\section{Referências}

ALBERTI, V. Histórias dentro da História. In: PINSKY, Carla Bassanezi (org.). Fontes históricas, São Paulo: Contexto, 2005.

ALMEIDA, M. E. B. Letramento digital e hipertexto: contribuições à educação. In: PELLANDA, N., et al. (org.). Inclusão digital: tecendo redes afetivas/cognitivas. Rio de Janeiro: DP\&A editora, 2005.

BAUER, M. W.; GASKELL, G. Pesquisa qualitativa com texto, imagem e som: um manual prático. 7. ed.. Petrópolis: Vozes, 2008.

BRASIL. Resolução FNDE/CD n 17 de junho de 2010. Estabelece normas e diretrizes para que os Municípios, Estados e o Distrito Federal se habilitem ao Programa Um Computador por Aluno-PROUCA. Disponível em: http://www.fnde.gov.br/programas/programa-nacional-detecnologia-educacional-proinfo/proinfo-projeto-um-computador-por-aluno-uca. Acesso em: 07/06/2019.

CHARTIER, R. A História Cultural: entre práticas e representações. São Paulo: Difel, 1990.

CHARTIER, R. Os Desafios da Escrita. São Paulo: UNESP, 2002. 
LEMOS, A. O que é cultura digital ou cibercultura? In: SAVAZONI, R.; COHN, S. (org.). Cultura digital.br. Rio de Janeiro: Beco do Azougue, 2009. p. 135-149.

LÉVY, P. As tecnologias da inteligência: o futuro do pensamento na era da informática. Rio de Janeiro: Ed. 34, 1993.

MORAES, R.; GALIAZI, M. C. Análise textual discursiva. Ijuí: Editora da Unijuí, 2007.

NEGROPONTE, Nicholas. A Vida Digital. São Paulo: Companhia das Letras, 1995.

RIGONI, D. M. Laptop educacional: mecanismos sociocognitivos nos contextos de aprendizagem. 2012. 128 f. Dissertação (Mestrado em Educação). Universidade de Caxias do Sul, Caxias do Sul, 2012.

SACRAMENTO SOARES, E. M.; BRUSTOLIN, R. K. Mudanças nas práticas docentes no contexto da inserção de laptops numa escola de ensino fundamental. Educação em Foco, Programa de Pós-graduação em Educação Universidade do Estado de Minas Gerais (UEMG), Belo Horizonte, ano 19, n.27, p. 73-95, 2016.

SACRAMENTO SOARES, E. M.; BRUSTOLIN, R. K. Mudanças nas práticas pedagógicas no contexto da inserção de laptops na sala de aula. Signos, Revista do Programa de Pós-graduação em Letras da UNISC, Santa Cruz, ano 36, n.2, p.82-95, 2015.

SACRAMENTO SOARES; MASCHIO, E. C. F. Práticas, representações e mediação: o uso dos laptops educacionais e as intervenções docentes no processo de aprendizagem da educação básica. Revista Ibero-Americana de Estudos em Educação (RIAEE), v.12, n. 2, 2017.

SACRAMENTO SOARES, E. M.; VALENTINI C. Tecnologias digitais: práticas e reflexões no contexto do ensino fundamental. Linhas, Revista do Programa de Pós-Graduação em Educação da UDESC, Santa Cruz, vol. 13, n.2, p.74-88, 2012.

SACRAMENTO SOARES, E. M.; VALENTINI C.; PESCADOR, C. O laptop educacional na escola pública: letramento digital e construção de significado. Revista do Programa de PósGraduação em Educação da UFSM, Santa Maria, v. 38, n.1, p. 151-164, 2013.

SCHMIDT, S. Tecnologias móveis na escola: movimentos da gestão escolar. 2016. 125 f. Dissertação (Mestrado em Educação) - Universidade de Caxias do Sul, Caxias do Sul, 2016.

SCHONZ, M. M. O laptop educacional na sala de aula: movimentos de letramento digital nas práticas de leitura e escrita de estudantes do ensino fundamental. 2013. 97 f. Dissertação (Mestrado em Educação) - Universidade de Caxias do Sul, Caxias do Sul, 2013.

YIN. R. K. Estudo de caso: planejamento e métodos. 3 ed. Porto Alegre: Bookman, 2005.

Recebido em agosto de 2019.

Aprovado em setembro de 2019. 
